\title{
Psychometric properties and correlates of three computer aversion scales
}

\author{
SCOTT T. MEIER \\ State University of New York, Buffalo, New York \\ and \\ MATTHEW E. LAMBERT \\ Texas Tech University, Lubbock, Texas
}

\begin{abstract}
Investigators have employed a variety of constructs and measures to examine individuals' discomfort with computer use. Models and instruments for measuring constructs such as computer anxiety, computer phobia, and computer aversion have been employed to investigate negative reactions that slow individuals' acceptance and useful application of computers. Using a large college student sample, we sought to compare the psychometric properties of three computer aversion scales and to investigate their relationships to gender, age, cognitive abilities, and experience with computer use. The results indicated good reliability, good validity coefficients, and similar factor structures for the scales. Younger students, female students, and students with lower mathematical skills and less computer experience were more likely to experience discomfort with computers. Implications include the possibility that if software and hardware alter subjects' expectations about the difficulty of completing tasks, individual differences in computer aversion are likely to become a source of additional unexplained variance. Such differences must be heeded in software design and in the design of experimental research involving computers as stimulus controllers and response recorders.
\end{abstract}

Individuals' discomfort with computer use has been observed and investigated in a variety of settings. For example, negative reactions to computers have been identified in high school and college students (Bandalos \& Benson, 1990; Loyd \& Gressard, 1984), business professionals (Gardner, Render, Ruth, \& Ross, 1985; Howard \& Smith, 1986), teachers (Elkins, 1985), hospital clerical staff (Kjerulff \& Counte, 1984), and mental health professionals (Meier, 1988; Super, 1970). Research in these diverse areas proceeds from a common hypothesis: Negative psychological reactions to automation slows both the acceptance and the useful application of computers.

Previous researchers have employed terms such as "computer aversion," "computer phobia," and "computer anxiety" to label negative psychological reactions to computers. We prefer to employ computer aversion, to avoid association with clinical phenomenon or personality traits. Meier (1985) defined computer aversion as negative affective reactions to computers with concomitant behaviors and cognitions. The following review of the research should provide an introduction to the area and indicate the state, as opposed to trait, nature of the construct.

Bandalos and Benson (1990) have noted that college courses increasingly require students to employ computers in coursework. Because of the efficacy of computer-assisted

Correspondence should be addressed to S. T Meier, Department of Counseling and Educational Psychology, 409 Baldy Hall, SUNY, Buffalo, NY 14260. instruction (CAI) programs (Chambers \& Sprecher, 1980; Flynn \& Kuczeruk, 1984), college students are encountering such programs in disciplines ranging from archaeology to statistics (Baerman, 1990). Moreover, math and test anxiety have been found to be frequent correlates of computer aversion (see, e.g., Marcoulides, 1988; Rosen, Sears, \& Weil, 1987), suggesting that students who have problems in these areas are also likely to experience difficulty working with computers. Thus, it appears likely that students who experience computer discomfort may have difficulty learning content presented through electronic media.

In the mental health professions, computer aversion has ramifications in two areas. First, computer-anxious clients who complete psychological tests administered by computer may produce test scores different from those produced by paper-and-pencil administration (see Hofer \& Green, 1985; Honaker, 1987). There is evidence that persons who take tests by computer may alter their rate of omitting items (Mazzeo \& Harvey, 1988), increase their "faking good" responses (Davis \& Cowles, 1989), and elevate scores on negative affect scales such as those that assess depression and anxiety (George, Lankford, \& Wilson, 1990). Second, acceptance of computer-based procedures-from expert systems to CAI and training applications-may also partially depend on mental health professionals' comfort with computer use (Meier, 1985). Mental health professionals, often primarily attuned to the interpersonal aspects of work, have a long history of apathy toward and rejection of computer applications. 
Given such issues, the reliable and valid assessment of computer-averse states would appear to be an important tool for persons interested in detection and remediation. In addition, discrepancies exist in the literature about such basic issues as the relationship between computer aversion and variables such as age, gender, cognitive abilities, and computer experience. For example, some studies have indicated that younger persons report less computer aversion (e.g., Nickell \& Pinto, 1986; Rosen et al., 1987), but in other studies (e.g., Ansley \& Erber, 1988; Honeyman \& White, 1987) no such relationship has been found. Conflicting findings may partly be the result of the wide range of sample sizes. For example, Meier (1988) reviewed computer aversion research and found 13 studies whose sample size ranged from 47 to $1,236(M=302$; median $=175)$.

In this study, we sought to investigate the psychometric properties of three computer aversion scales by testing a large college student population. Data was collected to (1) determine whether or not scale reliability and validity coefficients met acceptable test standards; (2) investigate possible gender and age differences on computer aversion scales; and (3) examine relationships between computer aversion and cognitive abilities and computer experience.

\section{METHOD}

\section{Subjects}

One thousand two hundred thirty-four subjects completed instruments at the beginning of this study as part of a research project in an introductory psychology course. Women constituted $51 \%$ of the sample $(n=625)$ and males $49 \%(n=608)$; gender information was unavailable for 1 subject. Mean age was $20.10(S D=4.08)$. The sample was predominantly White (86\%), followed by Hispanic $(8 \%)$, Black (3\%), Asian (2\%), and other (1\%). The majority of the sample were freshmen $(69 \%)$ and sophomores (20\%).

\section{Instruments}

Attitudes Toward Computer Scale (ATC). The ATC consists of 19 bipolar semantic differential type items designed to assess general attitudes toward computers (Kjerulff \& Counte, 1984). Kjerulff and Counte reported an alpha coefficient of .85 and found that the ATC predicted a hospital clerical staff's acceptance of a computerized management information system and their desire for further computer training. Sample items include "useful/ not useful," "frightening/nonthreatening," and "complicated/not complicated."

Computer Aversion Scale (CAVS). The CAVS is a 31-item true-false scale based on social learning theory (Meier, 1988). The CAVS produces four scores: (1) efficacy expectations for computers, a sum of items assessing beliefs about whether or not one can perform the behaviors required to operate a computer; (2) outcome expectations for computers, a sum of items assessing beliefs about whether or not one knows what behaviors are required to operate a computer; (3) reinforcement expectations for computers, a sum of items assessing beliefs about whether or not outcomes produced by computer use meet one's goals; and (4) total score, a sum of all items reflecting the cumulative effects of reinforcement, outcome, and efficacy expectations for computers. Sample items include "I would like to use a computer in my work" and "I feel incompetent when I try to use a computer."

In initial reliability and validity studies of the CAVS done with 270 undergraduate students, Meier (1988) found alpha coefficients of .89 for total score, .80 for efficacy expectations for computers, .81 for outcome expectations for computers, and .74 for reinforcement expectations for computers. No significant correlation was found between the CAVS and the Social Desirability Scale (Crowne \& Marlowe, 1964). The CAVS did correlate significantly $(r=-.53, p<.01)$ with the Attitudes toward Computer Scale (Rosen et al., 1987). Meier (1988) also subjected the CAVS to a principal components factor analysis with varimax rotation. Two factors included items from the reinforcement and outcome expectations subscales; a third factor included items from both the outcome and efficacy expectations subscales.

Computer Anxiety Rating Scale (CARS). Heinssen, Glass, and Knight (1987) have described a 19-item Likert scale designed to assess computer anxiety. Tested on a sample of 270 introductory psychology students, the CARS demonstrated good internal consistency $(\alpha=.87)$ and test-retest reliability over a 4-week interval $(r=.70$, $p<.01)$. The CARS was significantly related to a measure of computer experience and the Computer Attitude Scale (Loyd \& Gressard, 1984). Heinssen et al. (1987) also found significant correlations between the CARS and math anxiety, test anxiety, and SAT verbal and quantitative scores. These results indicate that computer-anxious individuals tended to report more math and test anxiety and to have lower SAT scores. Finally, a trend toward a significant gender difference on the CARS was found; women reported greater anxiety.

Sample items include "I look forward to using a computer on my job" and "It scares me to think that I could cause the computer to destroy a large amount of information by hitting the wrong key."

Computer Experience Questionnaire (CEQ). The CEQ is a newly developed scale designed to assess levels of experience with computers (Lambert \& Lewis, 1989). A 90-item scale, the CEQ requests information about amount and types of previous computer experience, particularly with regard to different computer applications. A coefficient alpha calculated on this sample equaled .89 . Sample questions include "How many hours a week do you use computers for coursework?" and "How many high school computer courses did you take?"'

\section{Procedure}

Data on the psychometric properties and correlates of the computer aversion scales were collected as part of a study designed to assess the utility of a CAI program employed in an introductory psychology course (see Lambert, 
Table 1

Means, Standard Deviations, and Reliability for Computer Anxiety Measures

\begin{tabular}{lccrc}
\hline Measure & $n$ & $M$ & $S D$ & $\alpha$ \\
\hline & \multicolumn{4}{c}{ Time 1 } \\
ATC & 1.234 & 93.69 & 20.30 & .92 \\
CAVS & 1.234 & 10.03 & 6.02 & .88 \\
CARS & 1.234 & 43.41 & 12.24 & .87 \\
& & Time 2 & & \\
ATC & 671 & 96.68 & 14.33 & .86 \\
CAVS & 664 & 9.02 & 5.99 & .88 \\
CARS & 671 & 44.40 & 11.78 & .87 \\
& & Time 3 & & \\
ATC & 1,130 & 93.59 & 24.04 & .96 \\
CAVS & 1.130 & 8.69 & 6.04 & .89 \\
CARS & 1.130 & 42.84 & 15.40 & .93 \\
\hline
\end{tabular}

Note-ATC $=$ Attitudes Towards Computer Scale $;$ CAVS $=$ Computer Aversion Scale; CARS = Computer Anxiety Rating Scale.

1990). The CAI program aided students' learning by providing practice quizzes, final examinations, performance reviews, and individualized study sessions.

Subjects completed the computer scales three times during the semester. These were Weeks 1,8 , and 15 of the semester, hereafter referred to as Times 1,2 , and 3 . Because the 32 sections of the course were structured differently, only about half of the initial subject pool was available at Time 2 . The CEQ was completed at the beginning and end of the semester (Weeks 1 and 15).

\section{RESULTS}

\section{Descriptive Statistics}

Means, standard deviations, and coefficient alpha are presented in Table 1. Alphas ranged from .86 (ATC, Time 2) to .96 (ATC, Time 3).

\section{Test -Retest Reliability}

Correlations across the three time points of the study are displayed in Table 2. For the ATC, test-retest re- liabilities ranged from .39 (Time 1-Time 3) to .51 (Time 2-Time 3). Test-retest reliabilities for the CAVS ranged from .74 (Time 1-Time 3 ) to .78 (Time 2-Time 3). For the CARS, test-retest reliabilities ranged from .47 (Time 1-Time 3) to .51 (Time 1-Time 2). These correlations underestimate the true reliability coefficients, because students received computer exposure during the semester.

\section{Convergent Validity}

Table 2 also displays intercorrelations among all total scores within and between the three time points. Within each time point, the CAVS and the CARS were highly correlated ( $r$ ranged from .62 to .67 ), while the correlations between the ATC and the other two scales were considerably lower ( $r$ from .14 to -.57 ). This pattern was maintained in the scale intercorrelations between the time points as well.

\section{Gender and Age Differences}

Analyses were conducted to search for gender differences at all three time points. At Time 1, women reported significantly higher CAVS and CARS scores $(t=-5.57$, $p<.01$, and $t=-3.85, p<.01$, respectively). A trend for gender differences on the ATC was also evident $(t=$ $1.71, p<.09$ ). At Time 2 , women had significantly higher CAVS scores only $(t=-3.25, p<.01)$. At Time 3 , gender differences were again evident for the ATC $(t=$ $2.03, p<.05)$, the CAVS $(t=-4.71, p<.01)$, and the CARS $(t=-2.50, p<.02)$. All of these findings indicate that on the total scores of the computer scales, women reported more discomfort with computers.

Subjects' age was also correlated with the scales' total scores at all three time points. Age was significantly correlated with the CARS at Time $1(r=-.09, p<.01)$, with no scales at Time 2 , and with the ATC $(r=-.06$, $p<.06)$, the CAVS $(r=-.08, p<.02)$, and the CARS $(r=-.13, p<.01)$ at Time 3 . These data indicate a small but statistically significant effect of younger subjects' possessing higher aversion scores.

Table 2

Scale Intercorrelations

\begin{tabular}{|c|c|c|c|c|c|c|c|c|c|}
\hline & \multicolumn{3}{|c|}{ Time 1} & \multicolumn{3}{|c|}{ Time 2} & \multicolumn{3}{|c|}{ Time 3} \\
\hline & ATC & CAVS & CARS & ATC & CAVS & CARS & ATC & CAVS & CARS \\
\hline $\begin{array}{c}\text { Time } 1 \\
\text { ATC } \\
\text { CAVS } \\
\text { CARS }\end{array}$ & & $-.25^{*}$ & $\begin{array}{r}-.03 \\
.67^{*}\end{array}$ & & & & & & \\
\hline $\begin{array}{c}\text { Time } 2 \\
\text { ATC } \\
\text { CAVS } \\
\text { CARS }\end{array}$ & $\begin{array}{r}.50^{*} \\
-.38^{*} \\
-.37^{*}\end{array}$ & $\begin{array}{r}-.47^{*} \\
.77^{*} \\
.55^{*}\end{array}$ & $\begin{array}{r}-.38^{*} \\
.45^{*} \\
.51^{*}\end{array}$ & & $-.57^{*}$ & $\begin{array}{r}-.55^{*} \\
.64^{*}\end{array}$ & & & \\
\hline $\begin{array}{c}\text { Time } 3 \\
\text { ATC } \\
\text { CAVS } \\
\text { CARS }\end{array}$ & $\begin{array}{r}.39^{*} \\
-.26^{*} \\
-.18^{*}\end{array}$ & $\begin{array}{r}-.29 * \\
.74^{*} \\
.45^{*}\end{array}$ & $\begin{array}{r}-.21^{*} \\
.55^{*} \\
.47^{*}\end{array}$ & $\begin{array}{r}.51^{*} \\
-.49^{*} \\
-.37^{*}\end{array}$ & $\begin{array}{r}-.36^{*} \\
.79^{*} \\
.46^{*}\end{array}$ & $\begin{array}{r}-.35^{*} \\
.61^{*} \\
.50^{\star}\end{array}$ & & $-.14^{*}$ & $\begin{array}{l}.14 \\
.62\end{array}$ \\
\hline
\end{tabular}

Note-ATC $=$ Attitudes Towards Computer Scale; CAVS = Computer Aversion Scale; CARS

$=$ Computer Anxiety Rating Scale. ${ }^{*} p<.01 . \dagger p<.05$. 
Table 3

Relationship Between Computer Anxiety Scales and Cognitive Abilities Measures

\begin{tabular}{|c|c|c|c|c|c|c|c|c|c|}
\hline \multirow[b]{2}{*}{ Measure } & \multicolumn{3}{|c|}{ Time 1} & \multicolumn{3}{|c|}{ Time 2} & \multicolumn{3}{|c|}{ Time 3} \\
\hline & ATC & CAVS & CARS & ATC & CAVS & CARS & ATC & CAVS & CARS \\
\hline SAT-Verbal & .03 & -.06 & .02 & -.05 & -.08 & -.03 & .04 & -.04 & .02 \\
\hline SAT-Math & $.11^{*}$ & $-.16^{*}$ & -.05 & $.11+$ & $-.22 *$ & $-.12+$ & $.13^{*}$ & $-.13^{*}$ & -.05 \\
\hline SAT-Total & $.09 \dagger$ & $-.13^{*}$ & -.03 & .05 & $-.18^{*}$ & -.10 & $.10^{*}$ & $-.10^{*}$ & -.02 \\
\hline ACT-English & $.13+$ & -.04 & .05 & .08 & $-.14 \dagger$ & -.11 & .02 & -.02 & -.10 \\
\hline ACT-Math & $.16^{*}$ & $-.18^{*}$ & -.01 & .07 & $-.27^{*}$ & $-.15 \dagger$ & .03 & $-.22 *$ & $-.16^{*}$ \\
\hline ACT-Total & $.15^{*}$ & $-.14^{*}$ & .02 & .07 & $-.28^{*}$ & $-.22 *$ & .04 & $-.16^{*}$ & $-.13 \dagger$ \\
\hline GPA & .06 & .02 & .01 & .03 & -.05 & -.03 & .01 & -.01 & -.04 \\
\hline
\end{tabular}

Note-ATC = Attitudes Towards Computer Scale; CAVS = Computer Aversion Scale; CARS = Computer Anxiety Rating Scale. ${ }^{*} p<.01 . \quad \dagger p<.05$.

\section{Relationships with Cognitive Ability Measures}

The relationship between computer aversion and measures of cognitive abilities has been examined in relatively few studies. To gain some sense of this relationship, seven proxy measures were selected: SAT scores (verbal, math, and total), ACT scores (English, math, and total), and cumulative grade-point average (GPA). These correlations are shown in Table 3. Unlike the other analyses reported in this study, where the $n s$ correspond to those shown in Table $1, n s$ varied across the cognitive ability measures. The largest data set was available for GPA $(n=880$ at Time 1) and the smallest for ACT English $(n=205)$; most $n$ s are in the 300-400 range.

In general, higher cognitive ability scores were negatively correlated with computer aversion measures. Math scores on the ACT and SAT correlated more highly with the computer aversion scales than did verbal or total scores. This relationship may reflect students' greater exposure to and competence with computer applications in math and science courses. Cumulative GPA showed no significant relationship with computer aversion.

\section{Computer Experience}

Table 4 contains the correlations between the CEQ and the computer aversion measures. Although all three aversion measures were consistently and significantly correlated with computer experience, the CAVS and CARS correlations consistently exceeded those of the ATC. Correlations indicate a small but stable relationship, which indicates that computer aversion decreases with greater computer experience.

\section{Factor Analyses}

Three factor analyses were performed on the ATC, CAVS, and CARS data collected at Time 1, the largest sample $(n=1,234)$. For the ATC and the CARS, no references to previous factor analyses could be found in the literature, and, consequently, both of the scales were subjected to a principal components analysis with varimax rotation. For the CAVS, Meier (1988) calculated a principal components analysis with varimax rotation to assess the validity of the three theoretical subscales of the CAVS. He found partial support for the model, although the outcome expectations and efficacy expectations subscales were highly correlated. For analysis of data in this study, a principal components analysis, set to extract three factors and with oblique rotation, was performed to test the stability of the factors previously found.

CAVS factor loadings above .30 are marked with an asterisk in Table 5; items that loaded above .30 in the Meier (1988) factor analysis are designated with a dagger. Thirty-seven percent of the total variation was accounted for with a three-factor solution. The eigenvalues of the three factors were $7.42,2.31$, and 1.71 , respectively. Factor 1 contains items from both the outcome expectations and efficacy expectations subscales, although the loadings are consistently higher on outcome expectations items. Factor 2 contains items predominantly from the efficacy and reinforcement expectations subscales; this factor was named negative feelings for computers by Meier (1988). Factor 3 items are solely from the reinforcement expectations scale. These findings are very similar to those reported by Meier (1988) and appear to confirm the basic factor structure of the CAS. Thus, two sets of items appear to tap dimensions assessing expectations about computer skills and usefulness of computers, respectively.

Table 6 displays factor loadings for the CARS. Three factors had eigenvalues above $1(6.59,2.22$, and 1.22 ,

Table 4

Correlations of Computer Experience and Computer Scales Variables

\begin{tabular}{lcc}
\hline & \multicolumn{2}{c}{ Computer Experience } \\
\cline { 2 - 3 } Measure & $\begin{array}{c}\text { Beginning } \\
\text { of Sermester }\end{array}$ & $\begin{array}{c}\text { End } \\
\text { of Semester }\end{array}$ \\
\hline Time 1 & $.15^{*}$ \\
ATC & $.06 \dagger$ & $-.24^{*}$ \\
CAVS & $-.14^{*}$ & $-.17^{*}$ \\
CARS & $-.14^{*}$ & \\
& Time 2 & $.19^{*}$ \\
ATC & $.11^{*}$ & $-.20^{*}$ \\
CAVS & $-.11^{*}$ & $-.23^{*}$ \\
CARS & $-.14^{*}$ & \\
& Time 3 & $.13^{*}$ \\
ATC & .02 & $-.23^{*}$ \\
CAVS & $-.11^{*}$ & $-.19^{*}$ \\
CARS & $-.18^{*}$ &
\end{tabular}

Note-ATC $=$ Attitudes Towards Computer Scale; CAVS $=$ Computer Aversion Scale; CARS $=$ Computer Anxiety Rating Scale. ${ }^{*} p<.01$. $\dagger p<.05$. 
Table 5

Oblique Rotated Factor Loadings for Theoretical Computer Aversion Scale Subscales

\begin{tabular}{|c|c|c|c|}
\hline $\begin{array}{c}\text { Item } \\
\text { Number }\end{array}$ & Factor 1 & Factor 2 & Factor 3 \\
\hline \multicolumn{4}{|c|}{ Reinforcement Expectations } \\
\hline 1 & .22 & $.36 *+$ & .29 \\
\hline 4 & .16 & $.61^{*}+$ & .22 \\
\hline 7 & .12 & $.45^{*}+$ & .21 \\
\hline 9 & .15 & .17 & $.43^{*}$ \\
\hline 11 & $.49^{*}$ & $.52 * \dagger$ & .15 \\
\hline 14 & .08 & .20 & $.59^{*}$ \\
\hline 17 & .14 & .18 & $.69^{*}$ \\
\hline 20 & .18 & .04 & .28 \\
\hline 23 & .16 & $.61^{*}+$ & .21 \\
\hline 27 & .16 & .13 & $.66^{*}$ \\
\hline 30 & .18 & .23 & $.54^{*}$ \\
\hline \multicolumn{4}{|c|}{ Outcome Expectations } \\
\hline 2 & $.75 * \dagger$ & $.31^{*}$ & $.04 \dagger$ \\
\hline 3 & $.74 * \dagger$ & .25 & $.08+$ \\
\hline 5 & $.67^{*}$ & .26 & $.13+$ \\
\hline 12 & $.64 *+$ & .06 & $.22 \dagger$ \\
\hline 15 & $.51^{*}$ & .19 & $.20 \dagger$ \\
\hline 18 & $.50^{*}$ & $.49^{*}$ & .20 \\
\hline 21 & $.64 *$ & .22 & $.18+$ \\
\hline 24 & .27 & -.03 & .21 \\
\hline 25 & $.47 *+$ & .13 & .08 \\
\hline 31 & $.71 *+$ & $.32^{*}$ & $.16+$ \\
\hline \multicolumn{4}{|c|}{ Efficacy Expectations } \\
\hline 6 & $.47 *$ & .14 & $.29 \dagger$ \\
\hline 8 & $.43 * \dagger$ & $.54 * \dagger$ & -.07 \\
\hline 10 & $.62 *+$ & $.45^{*}$ & .03 \\
\hline 13 & $.50^{*}$ & $.71 * \dagger$ & .12 \\
\hline 16 & .25 & $.75^{*}+$ & .12 \\
\hline 19 & $.35 *+$ & .25 & .09 \\
\hline 22 & $.57^{*} \dagger$ & .19 & .05 \\
\hline 26 & $.50^{* \dagger}+$ & .06 & .20 \\
\hline 28 & .27 & $68 * \dagger$ & .22 \\
\hline 29 & $.65 *+$ & $.44 *$ & .02 \\
\hline
\end{tabular}

* Factor loadings above .30. † Loadings above .30 in the exploratory factor analysis conducted by Meier (1988).

respectively); together they accounted for $50 \%$ of the variation. Factor 1 is composed of items that appear to assess respondents' negative feelings about computers (e.g., "I feel apprehensive about using computers"). Factor 2 contains items that measure users' positive feelings about computer use (e.g., "The challenge of learning about computers is exciting'). Finally, items that loaded on Factor 3 appear to tap a dimension concerning the user's ability to learn computer skills (e.g., "I do not think I would be able to learn a computer programming language"'). As with the CAVS, several items load on more than one factor. Factors again appear to represent affective reactions to computers and expectations about computer skills.

The ATC factor loadings are displayed in Table 7. Again, three factors had eigenvalues above $1(8.43$, 1.86 , and 1.23), which accounted for $61 \%$ of the variation. Items that loaded on Factor 1 include "good/bad," "efficient/inefficient," "slow/fast," "useful/not useful,", "time saving/time consuming," and "helpful/not helpful." This factor might be labeled usefulness of computers. Factor 2 included such descriptors as "overpowering/ easy to control," “"complicated/uncomplicated," " "boring/ interesting," and "competent/incompetent." These items appear to tap into a factor that could be labeled ease of computer use. Finally, Factor 3 items included "warm/ cold," "creative/not creative," and "exciting/unexciting." These items as a group could be labeled affective reactions to computers.

\section{DISCUSSION}

This research provided information regarding several basic areas of concern in the computer aversion literature. The computer aversion scales appear reliable, both

Table 6

Varimax Rotated Factor Loadings for the Computer Anxiety Rating Scale

\begin{tabular}{cccc}
\hline $\begin{array}{c}\text { Item } \\
\text { Number }\end{array}$ & Factor 1 & Factor 2 & Factor 3 \\
\hline 1 & $.60^{*}$ & .18 & .14 \\
2 & .29 & $.72^{*}$ & .14 \\
3 & .20 & .17 & $.51^{*}$ \\
4 & .25 & $.67^{*}$ & .24 \\
5 & .16 & $.43^{*}$ & $.60^{*}$ \\
6 & .02 & .12 & $.80^{*}$ \\
7 & .02 & .22 & $.79^{*}$ \\
8 & $.35^{*}$ & $-.51^{*}$ & .09 \\
9 & $.30^{*}$ & .03 & $.46^{*}$ \\
10 & .09 & $.52^{*}$ & $.49^{*}$ \\
11 & $.41^{*}$ & $.51^{*}$ & .23 \\
12 & $.30^{*}$ & $.30^{*}$ & $.44^{*}$ \\
13 & $.58^{*}$ & .26 & .18 \\
14 & $.74^{*}$ & .08 & .02 \\
15 & $.74^{*}$ & -.02 & .04 \\
16 & $.74^{*}$ & .13 & .19 \\
17 & $.46^{*}$ & .11 & $.40^{*}$ \\
18 & .17 & $.66^{*}$ & .28 \\
19 & $.73^{*}$ & .27 & .13 \\
20 & .15 & $.59^{*}$ & .29 \\
\hline
\end{tabular}

* Factor loadings above .30 .

Table 7

Varimax Rotated Factor Loadings for the Attitudes Towards Computer Scale

\begin{tabular}{cccc}
\hline $\begin{array}{c}\text { Item } \\
\text { Number }\end{array}$ & Factor 1 & Factor 2 & Factor 3 \\
\hline 1 & $.77^{*}$ & .16 & $.35^{*}$ \\
2 & .27 & .11 & $.63^{*}$ \\
3 & $.83^{*}$ & .10 & .20 \\
4 & $.57^{*}$ & $.34^{*}$ & -.04 \\
5 & $.84^{*}$ & .05 & .22 \\
6 & .26 & $.73^{*}$ & .11 \\
7 & $.79^{*}$ & .10 & .18 \\
8 & -.02 & $.73^{*}$ & .18 \\
9 & $.93^{*}$ & .11 & $.31^{*}$ \\
10 & -.04 & .21 & $.80^{*}$ \\
11 & $.46^{*}$ & $.40^{*}$ & $.53^{*}$ \\
12 & $.41^{*}$ & $.56^{*}$ & $.38^{*}$ \\
13 & .19 & $.53^{*}$ & $.36^{*}$ \\
14 & $.41^{*}$ & .05 & $.60^{*}$ \\
15 & $.65^{*}$ & $.38^{*}$ & .08 \\
16 & -.21 & $.31^{*}$ & -.24 \\
17 & $.35^{*}$ & $.64^{*}$ & .12 \\
18 & $.83^{*}$ & .17 & .28 \\
19 & $.46^{*}$ & $.35^{*}$ & $.56^{*}$ \\
\hline
\end{tabular}

*Factor loadings above .30 . 
in terms of internal consistency and test-retest reliability, and they demonstrate substantial convergent validity. Computer experience had a modest correlation with computer aversion, in the expected direction. Small gender and age differences also appear, indicating that younger and female students are more likely to experience discomfort with computer use. Cognitive ability measures indicate that more intelligent students report less computer aversion; interestingly, students' math ACT and SAT scores correlated more highly with computer aversion than did verbal or total scores. If computer discomfort is associated with poorer mathematics skills, use of CAI programs to correct deficiencies in math training may be particularly problematic.

Comparison among the three computer aversion scales suggests a slight advantage for the CAVS. While alphas were equivalent, the CAVS had consistently higher testretest reliabilities than did the ATC or the CARS. Regarding convergent validity, the CARS and the CAVS correlated consistently higher between themselves than either of them did with the ATC. This result suggests that the ATC should be considered a measure of general attitudes toward computer use rather than computer aversion per se. The CAVS appeared to be most sensitive to gender and cognitive ability differences, and the CARS, to age and computer experience differences.

Factor analyses with all three measures suggest that three factors may best explain psychological reactions to computers. First, an important factor has to do with people's expectations of what skills and technical knowledge are necessary to operate a computer. Second, individuals possess ideas about how useful a computer is-that is, about what applications might be appropriate for work or school. Third, items might be grouped under a heading called affective reactions to computers. These results, which appear to be very similar to those of other factoranalytic studies (Bandalos \& Benson, 1990; Gardner, Young, \& Ruth, 1989; Loyd \& Gressard, 1984), suggest that remediation programs should explain computer benefits as well as provide training and experience.

Although concerns about computer aversion have been raised predominantly in relation to areas such as instruction and testing, aversion may also represent a source of error in computer-based research. Meier (1988) suggested that types of tasks, presentation media, and person characteristics-all of which influence the demand on available cognitive capacity (Kahneman, 1973)-may interact to influence the results of experimental research. Change in any one of these factors may alter results. Thus, difficult mathematics items administered to low cognitive ability subjects via computer may produce different results than would the same task completed with paper and pencil by the same subjects. Given the theoretical models and empirical evidence for the computer aversion construct, it is quite likely that the means and standard deviations of math scores for the two groups would differ.

This research also has implications for laboratory-based studies. Computer aversion affects performance to the ex- tent that computerization alters the manner in which stimuli are presented, responses collected, and feedback provided. If software and hardware alter subjects' expectations about the difficulty of completing tasks, individual differences in computer aversion are likely to become a source of additional variance. Thus, computer aversion considerations are chiefly important in research programs in which experimental tasks have been transported to computers or even in which improvements in software and hardware may have altered subjects' expectations about the task. Of particular concern are subjects' outcome expectations about the computer-related knowledge and skills (e.g., finding the proper keys on a keyboard) required to participate in the research. Pretask instructions designed to familiarize subjects with the computer-based procedure may be helpful, but the extent of this problem and the effectiveness of methods to alleviate it remain to be studied.

Results of this study are limited by the predominantly Caucasian nature of the sample. Nonwhite subjects made up only $14 \%$ of the sample. In addition, $89 \%$ of the sample were university freshmen and sophomores; any generalizations about age, therefore, are restricted to a fairly narrow range. The results' generalizability are also limited by education. In the future, researchers should attempt to replicate these findings with diverse age, educational, and ethnic subject groups.

Convergent validity coefficients and factor-analytic results of this and other studies suggest that little evidence currently exists to support the discriminant validity of various computer aversion constructs. Researchers who maintain that the constructs (and measures) of computer aversion, computer anxiety, and computer phobia differ now have the burden of proof to demonstrate that such differences exist and are meaningful for assessment and intervention. More pragmatically, researchers performing work in these areas should review all of the relevant literature regarding previous research and instrument selection.

\section{REFERENCES}

ANSley, J., \& ERber, J. T. (1988). Computer interaction: Effects on attitudes and performance in older adults. Educational Gerontology, 14, 107-119.

BANDALOs, D., \& Benson, J. (1990). Testing the factor structure of a computer attitude scale over two grouping conditions. Educational \& Psychological Measurement, 50, 49-60.

BAERMAN, P. (Ed.) (1990). National collegiate software. (Available from Duke University Press, 6697 College Station, Durham, NC 27708).

Chambers, J. A., \& Sprecher, J. A. (1980). Computer-assisted instruction: Current trends and critical issues. Communications of the $A C M, 23,332-342$.

Crowne, D., MARLowe, D. (1964). The approval motive. New York: Wiley.

DAvis, C., \& Cowles, M. (1989). Automated psychological testing: Method of administration, need for approval, and measures of anxiety. Educational \& Psychological Measurement, 49, 311-320.

ELKINS, R. (1985). Attitudes of special education personnel toward computers. Educational Technology, 15, 31-34.

FlYNN, J., \& KuCzeruK, T. (1984). Computer-assisted instruction for the private practitioner. In M. Schwarz (Ed.), Using computers in clinical practice (pp. 153-177). New York: Haworth. 
Gardner, E., Render, B., Ruth, S., * Ross, J. (1985). Humanoriented implementation cures 'cyberphobia.' Data Management, 23, 29-46.

Gardner, E. P., Young, P., \& RUTH, S. R. (1989). Evolution of attitudes toward computers: A retrospective view. Behaviour \& Information Technology, 8, 89-98.

George, C. E., LANKFord, J. S., \& WILSON, S. E. (1990). The effects of computerized versus paper and pencil administration on measures of negative affect. Manuscript submitted for publication.

Heinssen, R. K., JR., Glass, C. R., \& KNight, L. (1987). Assessing computer anxiety: Development and validation of the Computer Anxiety Rating Scale. Computers in Human Behavior, 3, 49-59.

HoFer, P., GREEN, B. (1985). The challenge of competence and creativity in computer-based psychological testing. Journal of Consulting \& Clinical Psychology, 53, 826-838.

Honaker, L. M. (1987, September). The equivalency of computerbased and conventional tests: Current status. In L. M. Honaker (Chair), Computerized psychological testing: Current issues and future directions. Symposium conducted at the meeting of the American Psychological Association. New York.

HoneymaN, D. S., WhITE, W. J. (1987). Computer anxiety in educators learning to use the computer: A preliminary report. Journal of Research on Computing in Education, 20, 129-138.

HowARD, G., \& SMrTH, R. (1986). Computer anxiety in management: Myth or reality. Communications of the ACM, 29,611-615.

Kahneman, D. (1973). Attention and effort. Englewood Cliffs, NJ: Prentice-Hall.

KJerulfF, K. H., \& Counte, M. A. (1984). Measuring attitudes toward computers: Two approaches. In G. S. Cohen (Ed.), Proceed- ings of the Eighth Annual Symposium on Computer Applications in Medical Care (pp. 529-535). New York: Institute of Electrical and Electronics Engineers.

LAMBERT, M. E. (1990). Effects of incidental computer use during coursework on computer aversion. Manuscript submitted for publication.

Lambert, M. E., LeWIS, D. (1989). The Computer Experience Questionnaire. Unpublished manuscript.

LOYD, B., GRESSARD, C. (1984). Reliability and factorial validity of computer attitude scales. Educational \& Psychological Measurement, 44, 501-505.

MARCOULIDES, G. A. (1988). The relationship of computer anxiety and computer achievement. Joumal of Educational Computing Research, 4, $151-158$.

MAZZEO, J., \& HARVEY, A. L. (1988). The equivalence of scores from automated and conventional educational and psychological tests (Report No. 88-8). New York: College Board Publications.

MeIER, S. T. (1985). Computer aversion. Computers in Human Behavior, 1, 171-179.

Meser, S. T. (1988). Predicting individual differences in performance on computer-administered tests and tasks: Development of the Computer Aversion Scale. Computers in Human Behavior, 4, 175-187.

Nickell, G. S., Pinto, J. N. (1986). The Computer Attitude Scale. Computers in Human Behavior, 2, 301-306.

Rosen, L. D., SEArs, D. C., WeIL, M. M. (1987). Computerphobia. Behavior Research Methods, Instruments, \& Computers, 19, 167-179.

SUPER, D. E. (1970). Computer-assisted counseling: Present status and future developments. In D. E. Super (Ed.), Computer-assisted counseling (pp. 118-126). New York: Teachers College Press, Columbia University.

(Manuscript received June 4, 1990;

revision accepted for publication November 29, 1990.) 